\title{
JAK2 NP_004963.1:p.1960V
}

National Cancer Institute

\section{Source}

National Cancer Institute. AAK2 NP 004963.1:p.1960V. NCI Thesaurus. Code C105915.

A change in the amino acid residue at position 960 in the tyrosine-protein kinase JAK2

protein where isoleucine has been replaced by valine. 